This item was submitted to Loughborough's Research Repository by the author.

Items in Figshare are protected by copyright, with all rights reserved, unless otherwise indicated.

\title{
The indexical scope of adios: a relevance theoretic analysis of discursive constructions of gender and institutions and their impact on utterance interpretation
}

\section{PLEASE CITE THE PUBLISHED VERSION}

https://doi.org/10.1515/pr-2017-0050

\section{PUBLISHER}

(C) De Gruyter

\section{VERSION}

NA (Not Applicable or Unknown)

\section{PUBLISHER STATEMENT}

This work is made available according to the conditions of the Creative Commons Attribution-NonCommercialNoDerivatives 4.0 International (CC BY-NC-ND 4.0) licence. Full details of this licence are available at: https://creativecommons.org/licenses/by-nc-nd/4.0/

\section{LICENCE}

CC BY-NC-ND 4.0

\section{REPOSITORY RECORD}

Christie, Chris. 2019. "The Indexical Scope of Adios: A Relevance Theoretic Analysis of Discursive Constructions of Gender and Institutions and Their Impact on Utterance Interpretation". figshare. https://hdl.handle.net/2134/24621. 


\title{
Christine Christie*
}

\section{The indexical scope of adios: a relevance theoretic analysis of discursive constructions of gender and institutions and their impact on utterance interpretation}

https://doi.org/10.1515/pr-2017-0050

\begin{abstract}
The aim of this special issue of the Journal of Politeness Research is to show what happens when different analytical frameworks are be applied to a single piece of data: a short YouTube clip of a hearing in a USA courtroom. My specific aim in this paper is to show what an indexical analysis of (im)politeness phenomena, that is informed by a relevance-theoretic approach to communication, can bring to light about a short exchange between the judge and the defendant, that would not be evident to most viewers of this clip, and which also would not come to light through the application of the other methodologies demonstrated in this issue. Overall, I show that an analytical framework that takes a pragmatically informed indexical approach to (im)politeness phenomena, would predict and can explain variation between interpretations of an utterance as well as similarities in interpretation. It can therefore be used to address a problem that has always been present in (im)politeness analyses: how to identify and account for the social meanings generated by the use of a linguistic form in context.
\end{abstract}

Keywords: (im)politeness, indexicality, relevance theory, context, YouTube

\section{Introduction}

In this paper, I focus on a specific moment in the Soto hearing1: the exchange that immediately precedes (and triggers) the judge's doubling of the $\$ 5,000$

1 Details of the hearing, as well as a full transcription, are in the Introduction to this volume.

*Corresponding author: Christine Christie, Loughborough University, Loughborough, Leics, United Kingdom, E-mail: c.christie@lboro.ac.uk 
bail that he had previously set for Soto. In my analysis I apply an approach to (im)politeness that is informed by a pragmatics based on relevance theory, and a sociolinguistics based on indexicality theory. The grounds for this approach have been discussed in previous works (Christie 2007, 2013, 2014, 2015). Here my goal is to illustrate what this specific approach can bring to light about the use of language in the Soto hearing. In particular, I aim to show what an indexical analysis of (im)politeness phenomena, that is informed by a relevance-theoretic approach to communication, can bring to light about the exchange between the judge and Soto that would not be evident to most viewers of this clip and which also would not come to light in quite the same way through the application of other (im)politeness approaches to the courtroom data addressed in this volume. This is because the research questions asked here are specific to the approach I adopt. In this section, I begin with a brief statement of a problem that is faced by any (im)politeness analysis of the data. In Sections 2 and 3, I introduce and then apply the different elements that make up the theoretical framework I adopt. I conclude with a brief evaluation of the approach to (im)politeness presented in this paper.

\section{Overview of the paper and a statement of the problem}

In what follows, I focus on an exchange that lasts for only about five seconds, but is a pivotal moment in the hearing.

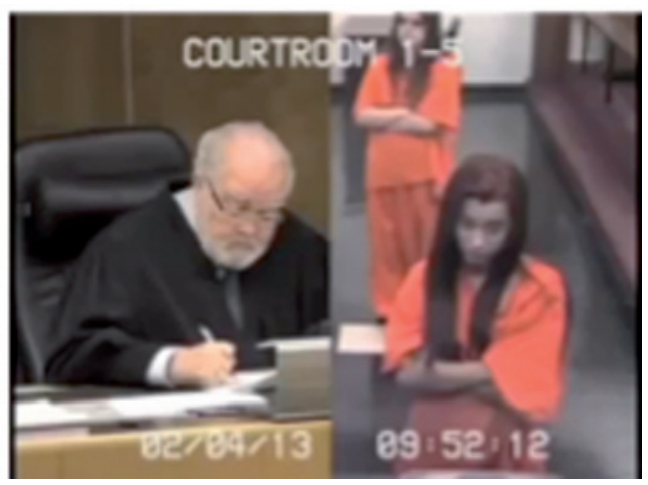

At the point in the Soto hearing where the digital counter (visible on the screenshot of the YouTube clip above) reads 9:52:12, the judge has already set Soto's 
bail conditions. He is in the process of making notes, and he appears to have finished with Soto's case. Five seconds later he looks up, looks to his right, looks down and then looks to his right again. On this second occasion he raises his hand and says, "Bye-bye". From this it would appear that what the judge has seen to his right is what we, as viewers of the YouTube clip, can see to the right of our screens: Soto is apparently waiting to be dismissed. Soto responds to the judge's bye-bye by smiling, leaning forwards and saying "Adios," before walking away.

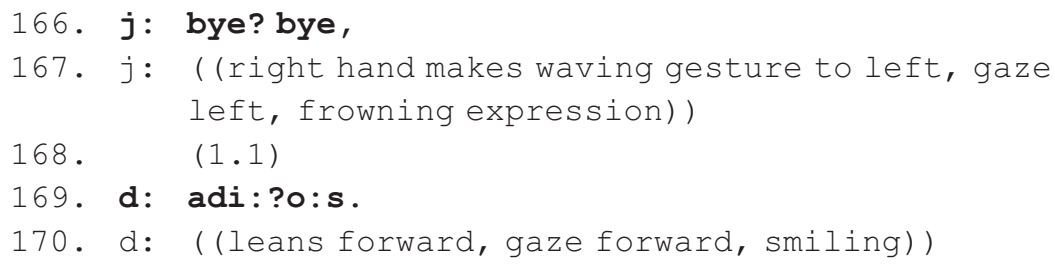

From this point onwards, the case takes a new direction: the judge calls Soto back and doubles the amount of her bail. Soto's reaction to this increase has further repercussions, leading to an order that she be jailed for thirty days.

The starting point of the analysis in this paper is the rather obvious inference that there is something about Soto's choice of the word adios, (possibly in conjunction with the way in which she says it and/or her posture when she says it) that is significant to the judge. In addressing this exchange from the perspective of an (im)politeness analyst, it seems self-evident that the change of direction in the court case is the result of conflicting (im)politeness evaluations by Soto and then the judge. Each participant appears to be making a series of judgments about what counts as appropriate interactive behavior in this setting, and there is clearly a mismatch in those evaluations, which in turn leads to an overt conflict between the judge and Soto. However, it is not at all obvious how these two utterances, bye-bye and adios, are actually intended or evaluated by the participants. And it is not self-evident how the subsequent behavior of either Soto or the judge, as the case later plays out, relates to those evaluations.

A specific problem about how to account for the (im)politeness evaluations informing the participants' behavior comes into view when actual interpretations of the exchange are considered. To illustrate the issue, I list some comments that were posted on the YouTube site in response to (1) above: ${ }^{2}$

2 These comments are part of the data set collected and analyzed in the study reported on here. The YouTube clip of the court case, headed Flipping the Bird to the Judge, was posted in February 2013 and these comments were collected in 2015. 
(2) This woman is a clown, but her "adios" was a pretty acceptable response to his cutesy "bye-bye."

(3) I think she meant "Adios" in sense "up yours" not in bye bye sense.

(4) A: Not a bad lesson: respect authority.

B: Where was she disrespectful? Or do you, like this judge, not understand what "adios" means?

The writer of (2) appears to interpret adios as an appropriate response to the judge's previous utterance. From this writer's perspective, Soto does not appear to have intended to be disrespectful. From an analytical perspective, then, if the utterance was not intended to offend, it would not appear to be an example of impoliteness (see Culpeper 2011). However, the writer of (3) appears to recognize that the use of adios in this context could be interpreted in at least two ways, and decides that Soto's utterance is an implied insult to the judge. From an analytical perspective, this would suggest that her utterance does appear to have been intended to offend and therefore it would be an example of impoliteness. Example (4) is an exchange between A and B and provides evidence of conflicting evaluations. The first writer (4A) judges Soto's use of adios as disrespectful: by categorizing the judge's action as a 'lesson', the implication is that this disrespect is what has triggered the judge's increase of the bail. In contrast, B's response to A here implies that Soto's use of adios is acceptable and any alternative interpretation is the result of a willful misunderstanding of the word adios.

Although in our everyday use of language, the meaning of utterances appears to be quite obvious, examples such as (2)-(4) show that not everyone will interpret the same utterance in the same way. This is one reason why, from an analytical perspective, it is far from clear how to account for what has happened in exchange (1) in a way that captures its significance for the participants, particularly given the impact this exchange has on the outcome of the case (that the other papers in this volume address in more detail). The problem I have identified here is not a new one for (im)politeness research. Brown and Levinson (1987: 280) point to the same difficulty when arguing that their theory of politeness can address a key issue in sociolinguistics at the time they are writing: how to identify and talk about "the origin and nature of the social valence attached to linguistic forms". For reasons that have been articulated in subsequent politeness scholarship, Brown and Levinson's model only goes so far in achieving their aim. In more recent years, indexicality scholarship in anthropology (see Agha 2003 and Silverstein 2003) has raised similar questions about the attribution of social meaning to linguistic resources, and my 
intention here is to show that some key tenets of the theory of indexicality that is currently informing sociolinguistics (see Blommaert 2007 and Eckert 2012) are of particular use in addressing a continuing problem for (im)politeness scholars: how to identify and account for the social meaning a linguistic form has generated.

However, as I have argued elsewhere (Christie 2013), the descriptive and explanatory power of the model of indexicality currently adopted by sociolinguistics is limited because, although it provides a useful account of the cultural conditions through which linguistics resources are able to index social meanings, it cannot account for the process of meaning generation itself. My point is that indexicality theory needs to be supplemented by a pragmatic account, such as relevance theory, which does address the process of meaning generation. The research questions driving this study (and which led to the collection of the data exemplified in (2) to (4) above) are therefore grounded in these two theoretical frameworks. I set those research questions out here and then address them in more depth in Sections 3 and 4.

i. Is there evidence of variation in (im)politeness evaluations of Soto's use of adios in exchange (1)?

ii. Is there evidence that variations in the evaluation of Soto's use of adios in exchange (1) correlate with variation in what hearers perceive to be the context of the exchange?

iii. What do the findings of $i$ and ii tell us about exchange (1) that would not be immediately evident to a lay audience of the exchange and would not be brought to light by alternative analytical approaches?

My primary goals in the following sections are to show how the two frameworks I adopt both predict and explain how Soto's use of adios comes to generate different and sometimes conflicting interpretations and then to identify patterns that can be help to explain overlapping interpretations about the (im)politeness value of that utterance.

\section{Identifying variation in (im)politeness evaluations of adios}

Indexicality, when it is applied to language, refers to the use of any linguistic resource (a tone of voice, a specific word, a syntactic structure,) to call to mind an idea or an object without actually describing or referring to that idea or object (see Pizziconi and Christie 2017). The theory of indexicality developed 
by Silverstein $(2003,2010)$ provides an inclusive framework for understanding this process by rethinking the relationship between language and culture. Although many of the issues that the indexical approach engages with are not new to (im)politeness scholarship, seeing these issues through the lens of an indexical approach links them in unforeseen ways and, in doing so, offers a more elegant and comprehensive explanation for them than has previously been available. As Silverstein (2003: 194) asserts, the notion of indexicality brings "theorized order to a large number of what once appeared to be disparate phenomena". The indexical approach to language that has been developed within third-wave sociolinguistics (see Eckert 2008, 2012) draws on Silverstein's (2003, 2010) work on indexicality, However, in this section I draw on the theorization of indexicality formulated by Ochs (1996). This version precedes much of the theoretical scaffolding that Silverstein and others have provided but, for the purposes of this study, it provides an approach that is easy to operationalize and also provides a sufficient explanation of the data. In the conclusion to this paper I show how this explanation relates to the broader theorization of indexicality.

For Ochs (1996) indexicality is a function of acculturation. She proposes that "socialisation is in part a process of assigning situational, i.e. indexical, meanings ... to particular forms", and she goes on to define such forms in the following terms:

A linguistic index is usually a structure (e.g. sentential voice, emphatic stress, diminutive affix) that is used variably from one situation to another and becomes conventionally associated with particular situational dimensions such that when that structure is used, the form invokes those situational dimensions. (Ochs 1996: 411)

A structure that is conventionally associated with a particular social dimension might be an intonation pattern such as the use of a rising tone at the end of a declarative sentence. This resource can become indexical where there is a particular social dimension within which it typically recurs and with which the form therefore becomes associated by language users in a culture. In Britain in recent years, the most consistent use of this specific form has been associated with a particular demographic: teenage girls. This association has been maintained over a number of years since those same girls who have used this form consistently as teenagers are unlikely to continue to use it to the same extent when they reach their late teens and early twenties, but new generations of teenage girls have in turn used this form. So for those British speakers of English who associate raised intonation at the end of a declarative sentence with teenage girls, the form would be indexical because it invokes a situational dimension: in this case the social category of the typical speaker. This associa- 
tion is transient however: at some point in the future when teenage girls no longer use this form, it will no longer index that demographic (even though, for those who have lived in Britain in the early $21^{\text {st }}$ century, the association will still be possible).

Ochs' point is that when children are born into a culture, or when speakers of another language learn the language of a new culture, the acculturation process involves the acquisition of an understanding of which linguistic resources index which social dimensions in that specific culture at that point in time. This is a key communicative tool since this knowledge of a link between a resource and a context of use allows members of a culture to use that resource creatively with others who share that association. Also, where sufficient members of a culture develop a conventional association between a particular form and a particular set of situational dimensions, that same form can become 'enregistered' (see Agha 2003 on the enregisterment of Received Pronunciation for an illustration of this process) and can be used to invoke aspects of the original situational dimensions when it is used outside of those original situational dimensions.

Seeing language from an indexical perspective allows us to address many different contributory elements and effects of meaning generation. Ochs (1996: 410) proposes that linguistic resources that have acquired a conventional meaning can be employed by speakers to index a particular social identity, social stance or social act. A key contribution that this notion of indexicality has made to sociolinguistics is to highlight the fact that social identity has many different aspects: roles (e.g., speaker, over-hearer, doctor, lecturer); relationships (e.g., kinship, occupational, friendship): group identity (e.g., gender, generation, class): and rank (e.g., employer and employee): and that these are indirectly constituted through acts of indexicality (see Bucholtz 2009; Moore and Podesva 2009). The theory proposes that, since as speakers we use language reflexively, in any given interaction we are able to select the linguistic resources we judge to be recognizably appropriate to that interaction, taking into account our own and others' social roles and what language choices are typically made in particular contexts of use. For example, a speaker will talk like a mother when with her child, like a doctor when with patients and like a professional at board meetings. This is not just a matter of using a register: from this perspective, as with other performative accounts, using specific linguistic resources is a means through which social roles and social identities are constituted and perpetuated.

Significantly, however, a resource that has acquired a conventional link with a particular demographic can become a semiotic resource available for use outside of its typical situational dimension in order to index something 
extra about speaker identity or an attitude towards a situation. Indexicality is always indirect in that the resource and the social meanings it might generate are always mediated by cultural knowledge and cultural practices. A particular tone of voice or phrase in a particular culture might index a social act (i.e., a socially recognized type of goal-directed behavior) such as an invitation, a compliment or a dismissal. Or those same resources might index a particular epistemic or affective stance, which is then recognized as typical of certain social identities. Although this indexical potential derives from shared associations, they are not fixed, and the associations and the social meanings indexed therefore have the potential to change with every iteration (see Eckert 2008).

The judge's use of bye bye in (1) above offers a useful illustration of what Ochs' indexicality model has to offer an (im)politeness analysis. Here, I use this utterance to introduce some of the questions that an indexical approach to (im)politeness would lead an analyst to ask, but since the judge's utterance is also referred to in the data I discuss below, I also use this discussion to identify some of the specific issues that the judge's utterance raises so that I can develop them in the data analysis.

An initial question that any indexical approach would ask in relation to an utterance such as the judge's use of bye-bye is:

(5) What are the situational dimensions that a hearer would typically associate with the use of this linguistic form?

At this stage in my argument, my aim is relatively limited: I am using Ochs' approach to show why the meaning of exchange (1) is not self-evident to an analyst. However, where this question is asked in sociolinguistic studies and in relation to a particular linguistic variable, such as the use of tag-questions or slang terms, then the answer would typically be addressed through a sociolinguistic survey or through the use of corpus data (see, for example, Bucholtz 2009; Moore and Podesva 2009). However, to meet the needs of my argument at this stage of this paper, I use my own interpretation of the form to illustrate the sort of answer that (5) might generate through more systematic means in a sociolinguistic survey.

The primary situational dimension with which I associate the use of byebye - particularly when spoken with the intonation used by the judge - is a playful or light-hearted interaction between an adult (typically a parent and typically a user of standard British English) and a young child, a secondary dimension of use would be a child to child interaction. A second question that an indexical approach would then ask is: 
(6) When this resource is used in what is perceived to be its usual situational dimension, what social meanings (i.e., what type of social identity, affect, or other situational meaning) does it index?

From my own set of associations, it would follow that any use of this form by an adult speaker of standard British English to a child would index their relationship as a specifically 'adult-child' relationship. As Ochs' structure (1996: 416) argues, the use of indexical forms has the potential to constitute a social meaning, such as a social identity or a social relationship. Because the indexical potential of a form derives from "its history of usage and cultural expectations surrounding that form" (Ochs 1996: 418), it is available as a resource through which parents or other adults can actively realize and configure their relationship with a child as a relationship with a child. This reflexive use of language illustrates how our acquired knowledge about the indexical potential of forms enables us to use language to construct and perpetuate different social identities and social relationships.

As proposed above, a form can be used to constitute a particular social relationship or identity when it occurs within its usual situational dimension of use and, where that association has become conventionalized, the use of the form is also available for semiotic exploitation in other situations. A third question an indexical approach would therefore ask is:

(7) When this resource is used outside of what is perceived to be its usual situational dimension, what social meanings (i.e., type of social identity, affect, or other situational meaning) does it index?

Again, depending on the aims of a study, this answer could be addressed by drawing on, and analyzing, many different types of data. But to use my own interpretation as an illustration: given the social relationship that, for me, is typically indexed through the use of bye-bye, when I interpret the judge's utterance he appears to be indexing an affective stance of playfulness or affection and is also indexing an 'adult to child' social relationship with his addressee.

Linguistic resources can be used to index social rank as well as social relationships, and in this context, a supplementary question would immediately be raised about the judge's utterance: would we expect to hear those words spoken in that tone addressed by someone of a higher rank to someone of a lower rank in an institutional setting? Because of what that form indexes for me, as a member of British culture, I would not, for example, expect to hear such an utterance in the context of a doctor speaking to an adult patient, or a CEO to a worker in her company. Since indexical meanings are constitutive 
(i.e., speakers can constitute themselves as performing the social rank of 'boss' or 'parent' through the reflexive use of linguistic forms that have acquired a conventional association), the judge, through the use of this form, appears to me to be implying that his social rank is deliberately not being indexed at this point in the hearing. He appears to me, therefore, to be indexing the social role of parent and an affective stance of indulgence. It should come as no surprise then, to learn that I see Soto's use of adios as a playful response to what appears to be a playful form of dismissal by the judge.

I have used the judge's utterance of bye-bye here, and the associations that the form raises for me, to illustrate some of the premises that underlie an indexical approach and some of the questions that such an approach would ask in relation to situated uses of forms such as this. However, an indexical approach would predict that my own interpretation is not the only possible interpretation. From this perspective, the relationship between a linguistic form and the social meanings it generates is not denotative: there is no fixed link between a linguistic resource and any social meanings it might index. As Ochs, (1996: 413) argues:

Interlocutors may use these structures to index a particular identity, affect, or other situational meaning; however, others co-present may not necessarily assign the same meaning.

Indexical meanings, by definition, are generated inferentially, and the theory posits that inferences are based on interlocutors' experiences of patterns of usage that link resources to social dimensions. Therefore if, as indexicality theory argues, social meanings are generated through the patterned association of linguistic resources to social dimensions, the theory would predict that indices are open to different interpretations: the same social meaning will only be inferred if two interpreters call up the same set of associations. For example, only those hearers who made the same association as me when I first heard the clip (the linking of parent-child speech to the judge's use of bye-bye) would come up with the same interpretation as me: that the judge is indexing the social role of indulgent parent through his utterance of bye-bye.

This prediction is what informs my first research question in relation to the indexical value of adios:

i. Is there evidence of variation in (im)politeness evaluations of Soto's use of adios in the clip?

In order to address this first question, I used the YouTube comments that accompanied the clip of the court case entitled Flipping the Bird to the Judge 
that was posted in February 2013. At the point at which I began to look for interpretations of the bye-bye/adios exchange, there were more than 40,000 comments listed. Using adios as a search term, I extracted from that corpus only those comments that included the word adios or else were part of an exchange with someone who had posted a comment that had mentioned Soto's use of adios. ${ }^{3}$ It was immediately evident that there were many different interpretations of Soto's utterance and many different accounts of how her utterance led to the problems she subsequently found herself facing. I stopped collecting examples to analyze when I had reached fifty since these already provided an answer to my first question: yes there is evidence of variation in the (im)politeness evaluations of the utterance.

In this section, I point to just three types of interpretation in order to illustrate how the interpretations vary in their articulation of the stances, social roles, group identities and social rank indexed by the utterances in (1).

\subsection{Type A interpretations}

These derive from a similar set of associations to those I have outlined above: the judge's utterance is seen as indexing a playful stance, and is not seen as indexing the social role of 'judge' or the rank of 'judge' in a judge/defendant pairing. Such interpretations present Soto's use of adios as an acceptable (if not exactly wise) response since it also indexes the playfulness and an equality of rank indexed by the judge. This example of a Type A interpretation was briefly introduced in Section 2:

(8) This woman is a clown, but her "adios" was a pretty acceptable response to his cutesy "bye-bye."

Although this interpretation is not particularly sympathetic to Soto, it appears to be premised on a similar association between the use of bye-bye and the typical context of use that came to my mind. Soto's behavior is predicated on the assumption that the judge is treating her playfully and (by not overtly indexing the superior rank of 'judge' in a judge/defendant pairing) is indexing a lack of rank. The categorization of Soto as 'a clown' suggests that her use of adios is not the most sensible choice, but the interpretation implies that there is

3 Working out whether a comment is part of an exchange is by no means straightforward, however. Sometimes exchanges are embedded as replies to a comment, but at other times one contributor will indicate that they are replying to an earlier contributor only through the use of the previous contributor's username. 
no reason for Soto's utterance to be evaluated as disrespectful. In the following exchange, the second turn here, (9B) was cited in Section 2 and it appears to be a response to a comment made some time previously in the string (9A [3 in section 2]). I have included the first part here as it illustrates a Type A interpretation and, also shows that these associations are available to (9B). However, these associations are not applied in (9B's) interpretation of Soto's use of adios.

(9) A: i dont condone her behaviour but neither do i condone his, he was very childish as well. Bye bye is quite childish and regardless of anything he still disrespected her, he didnt need to taunt her, which he did.

B: I think she meant "Adios" in sense "up yours" not in bye bye sense.

\subsection{Type B interpretations}

Type B interpretations (such as [9B]) present Soto's use of adios as indexing an oppositional stance. Often, in the data, this is because adios is presented as indexing an equal rank with the judge, and Soto is therefore seen as failing to index her inferior rank in comparison to the institutional rank and the social role of a judge. In the data, this is frequently also seen as failing to index the respect due to the institutional setting itself as in (10A's) comments here. The following exchange is a development of exchange (4) cited in Section 2.

(10) A: And I suppose you believe her flipping the bird was also a correct and ethical form of behavior in the courtroom. Please, keep defending contempt of court acts, you are too amusing

B: You can be amused all you like, but it doesn't change simple facts. She only flipped him off AFTER he changed his ruling which was obviously based purely on personal spite. Him mimicking her saying "adios” immediately after the alteration only reinforces that observation. You can irrationally blame her all you like, but if you follow the chain of events you'll find that there was no disruption of the court until after his blatant abuse of authority. It all starts with him and his ego.

A: he charged her more because clearly she took everything lightly, giggling and smiling as if her being in there is a joke. He wanted to get the point across to her that whatever she did she should feel bad about so he changed it to $\$ 10 \mathrm{k}$.

This exchange illustrates one of the clearest divisions between Type A and Type $\mathrm{B}$ interpretations. On one side there is the perception that the judge is being 
unreasonable since his use of bye-bye is the reason Soto replied with adios, while on the other there is an assumption that Soto deserves to be punished because she is insufficiently respectful. There were a number of comments which, like (9A), justify the judge's behaviour in doubling Soto's bail by citing her failure to take her situation sufficiently seriously. Many of these, as in the comment below, see her behavior as gendered:

(11) She really should have been listening and not been giggling like a girl who thought she was getting off easy. Props to the judge, kids need a reality check at some point and he just gave her a reality hockey check

\subsection{Type $\mathrm{C}$ interpretations}

Type C interpretations present Soto's use of adios as indexing a particular social identity. In many such interpretations she is presented as indexing an affective stance of 'cuteness' which in turn indexes a social identity that is gendered in that it is feminine and negative in that it is manipulative. These latter social meanings are not attributed to Soto as having been intentionally indexed by her behaviour, but this is what this behavior indexes for these interpreters.

(12) The original point is that in court, if you are arrested, freedom of speech does not apply. You lose certain freedoms when you're arrested and they tell you that when you're arrested. And anyway, the adios thing, the judge is Hispanic, he knows what it means, but I'm pretty sure she said it in a mocking, "cutesy" way since he just let her off. That's a problem with some girls, they think acting cute will get them out of trouble just because they're girls. Nope. Not this time.

This interpretation presents Soto's use of adios as indexing a mocking stance and her behaviour generally is presented as the realization of a gendered set of resources. The writer of (12) does not relate Soto's use of adios to the judge's use of bye-bye. Instead adios is presented as inappropriate in the light of the assertion that a person who is arrested has limited freedom and cannot say whatever she wants to say. The judge's punitive behavior is seen as justified because Soto's use of adios here is not indexing a sufficiently respectful stance given the institutional setting. What marks Type $C$ interpretations as different to Type B interpretations is their presentation of the affective stance that is indexed by Soto (e.g., 'cutesy' or 'mocking') as, in turn, indexing a particular 
social identity: that of a manipulative female who uses her gender to her advantage. This view is presented in the following interpretation:

(13) She thinks because she's a girl, she can get away with everything

In Type C interpretations, then, Soto's use of adios indexes a particularly female form of privilege.

The variation in interpretations here would be predicted by an indexical approach to the data. If different members of a culture have different experiences, they would associate any given linguistic resource with different social dimensions of use, and this would, in turn, lead to the indexing of different social meanings for these members. However, while this approach brings into view the links between cultural contexts of use and different interpretations, it is not able to account for utterance interpretation itself and it leaves many questions unanswered. For example, I would argue that most hearers of (1) would have had no difficulty recognizing the association between the judge's use of bye-bye and the situational dimension of an adult-child or child-child interaction that I outlined above. If that information is potentially available to every interpreter, it is unclear why every hearer of the exchange between Soto and the judge did not make the same association when first interpreting the exchange that I did. And if they did, it is not clear why all the hearers did not take that into account when judging Soto's use of adios and as a result see it as a relatively inoffensive echo of the informality the judge has just indexed. Equally, if all the interpreters, including me, know that exchange (1) is taking place in an institutional setting, where respectful behaviour is expected from those of lower rank, it is not clear why everyone (including me) did not come up with Type 2 interpretation, that Soto's use of adios is offensive because it is disrespectful. In order to explain the variation in the interpretations, it is necessary to understand how interpretations occur, and the following pragmatic account of utterance interpretation is designed to do this.

\section{Explaining variation in interpretation}

In Section 2, I argued that, from an (im)politeness perspective, it is not obvious how either of the two utterances that constitute exchange (1) is intended by the speaker or evaluated by the addressee. However, from a relevance-theoretic perspective, it would be predicted that in normal circumstances (i.e., when an interaction is just an interaction and not the object of analysis) the meaning of (1) is likely to be immediately obvious to anyone who heard it, whether they 
were hearing it at first hand during the court case or later, as a result of viewing a YouTube clip of the case. Relevance theory (Sperber and Wilson 1995) would predict that as soon as Soto uttered the word adios, any hearer of this exchange would (as long as he assumed that the two speakers were saying something that was of relevance to the court case) immediately be able to interpret and evaluate Soto's communicative intention. Moreover, if a hearer had come up with an interpretation of Soto's meaning, he would also be able to immediately provide a rationale for his interpretation, as well as an explanation for the judge's reaction to her utterance. Even if a viewer were to continue to speculate about the behavior of the interactants, or ponder on it later in the light of new information, it would be in response to that initial set of immediate, and obvious interpretations.

This prediction derives from two tenets of relevance theory: (1) in the act of utterance interpretation, a hearer looks for a satisfactory interpretation that provides maximum benefit for minimum effort and (2) the most obvious interpretation of an utterance will be the most relevant one for that hearer. Here tenet (2) is a logical conclusion of tenet (1): because there would be no reason to expend further effort looking for another interpretation when a satisfactory (i.e., a relevant) interpretation has been arrived at, a hearer will stop processing an utterance the moment he arrives at, what is for him, the most obvious interpretation of that utterance. In this section, I explain and build on these tenets, focusing in particular on the process of interpretation and the model of context that relevance theory posits. My aim is to show how the indexical framework outlined above complements the relevance theoretical model of context as dynamic and emergent: i.e., as a function of utterance interpretation rather than a set of assumptions that precede an utterance. I then address the data in the light of an analysis that links the content of contextual assumptions with the culturally acquired associations posited by indexicality theory.

Relevance theory posits that human beings tend to filter out any information that is not immediately relevant to them. For example, we don't tend to notice how many people sitting near us on a bus are wearing black shoes unless we happen to have a particular interest in shoe colour that makes it worth our while noticing it. Our perception processes are so efficient at filtering out irrelevant phenomena that for the most part these phenomena do not even reach our consciousness. For language to have evolved as such an effective medium for communication (irrespective of the other functions it has), therefore, human beings must have developed a particular sensitivity to the use of language that cuts through this filtering process. In arguing this view, Wilson (2011) proposes that, when we hear utterances, a specific type of interpretive process is triggered that is quite unlike the process we use when interpreting any other exter- 
nal stimuli, and she goes on to claim that "understanding utterances involves special-purpose inferential procedures that apply only in the communicative domain" (2011: 194). From a relevance theoretical perspective, these inferential procedures are triggered because every utterance raises very strong and specific expectations of relevance in the person it is addressed to. The theory posits that these expectations alone are sufficient to guide a hearer towards a speaker's intended meaning.

A crucial expectation that is raised when an utterance is addressed to a hearer is that it will have 'optimal relevance'. In everyday terms, an utterance that is optimally relevant is one that enables the hearer to reach a satisfactory interpretation, without putting him to a lot of effort in arriving at that interpretation. In relevance theoretical terms, to be optimally relevant, an utterance (as an input into the hearer's interpretation process) must convey a sufficient number of 'contextual implications' (as the outputs of that process) to be worth the hearer's attention. Moreover, the hearer should be put to no unjustifiable effort in obtaining these 'outputs'. The raising and satisfying of expectations of optimal relevance is not a matter of volition on the part of the speaker or the hearer. As Wilson and Sperber (2012: 6) argue, "Speakers may fail to be relevant but they cannot, if they are genuinely communicating (as opposed say, to rehearsing a speech), produce utterances that do not convey a presumption of their own relevance". It is this presumption of relevance that triggers in a hearer what is referred to as the "relevance guided comprehension heuristic" (Sperber et al. 1995: 51). This heuristic states that, on hearing an utterance an addressee will:

(a) Follow a path of least effort in constructing an interpretation of an utterance

(b) Stop when his expectations of relevance are satisfied

The expectation of relevance and the heuristic go some way to explaining the range of interpretations evidenced in the data. The data consists of comments from viewers who have already come to a point when their expectations of relevance have been satisfied: each writer has already arrived at the interpretation of the exchange between the judge and Soto that is most obvious to him because it is the one that is most relevant to him. In the language of relevance theory, this interpretation is the output that the exchange between the judge and Soto has yielded for the hearer. However in order to understand why there are so many different interpretations in the data, we need to take a closer look at the inputs into that process.

Relevance theorists assume that what a speaker says (i.e., what her words mean) and what a speaker means by using those words are two distinct types 
of meaning that need different types of explanation. However, both types of meaning are contextually derived. This is because, as speakers we can never fully 'encode' our meaning in our utterances and this is because language underdetermines meaning. For example, every word in English can be used to convey many different meanings, even though we tend to assume that words have a 'literal meaning'. It is therefore the task of the hearer to infer the specific meaning that a particular word is intended to convey to him when it is used in a particular context. For example the judge's utterance of the words come back immediately after Soto has said adios, has a particular, explicit meaning in that context which conveys something along the lines of 'return to where you were previously standing'. But the utterance come back in another context might mean 'return to the place where you have previously been living'. So although the word back has a conventional meaning in that it roughly refers to 'a previous state', working out what the word back means in a specific context of use is the result of the pragmatic inferences generated by the hearer (but anticipated by the speaker when phrasing that utterance).

Although what is 'said' (the explicatures of an utterance in relevance theoretical terms) is context dependent, this type of meaning can be seen as having been derived directly from the words used. However, what a speaker means by what she has said is a type of meaning that cannot be derived directly from the words that are used. For example, in saying come back the judge might intend to convey the meaning 'I haven't finished with you yet'. But in another context, these same words might be used by a speaker to mean 'I miss you'. In either case, this type of meaning (the contextual implications of an utterance in relevance theoretical terms) cannot be derived directly from the words that are used. And the key issue here is that if a hearer is able to arrive at this second type of meaning he must draw on a set of 'contextual assumptions' to supplement the explicit meaning of the utterance (see Blakemore 2011: 120 for a more extended treatment of this issue).

An interpretation (contextual implication) as an output therefore requires two inputs, both of which are pragmatically inferred by the hearer: the first input is the set of explicatures the hearer infers that the utterance has generated on the basis of what has been said and the context in which it is said; and the second input is the set of contextual assumptions he believes the speaker intends him to access when working out what she means by what she has said. It is this aspect of the relevance theoretical framework that leads to the second of my research questions:

ii. Is there evidence that variations in the evaluation of Soto's use of adios in exchange (1) correlate with variation in what hearers perceive to be the context of the exchange? 
Again, when this question is applied to the data, the answer is yes. If we take the forms adios and bye-bye to be terms that conventionally signal a departure, then we can infer that what both interactants have 'explicitly' said is 'goodbye'. But for a hearer to work out what the speakers meant by what they said when choosing to use these specific forms for saying 'good-bye' he needs to draw on a relevant context, that is to say, on a relevant set of contextual assumptions.

For example, both bye-bye and good-bye might be ways for the judge to convey the contextual implication:

(14) You can go now.

From a relevance theoretical perspective, however, since any utterance raises the expectation of optimal relevance, the hearer expects every choice that goes into that utterance to function as a guide to the speaker's intended meaning. So, choosing to say bye-bye rather than good-bye, or even the more explicit you can go now, carries an expectation that the choice will have some relevance to the addressee beyond the dismissal that would be implied by the other two forms. Equally saying adios rather than nodding, turning around and leaving in silence carries the expectation that this use of this particular word at this particular moment will have a relevance for the addressee beyond a simple acknowledgement of that dismissal. If the addressee (or indeed any hearer, such as a YouTube viewer) is able to come to a conclusion about what a speaker means by what she has said, therefore, it is because he is able to access a set of contextual assumptions that would account for the relevance of the speaker's choice of words.

The interpretations that make up the data suggest that the hearers of the clip were accessing a range of different contextual assumptions when interpreting the words used by Soto and the judge. Differences are particularly evident when an interpretation is being defended in an exchange as, in such cases, the writer often justifies his interpretation by articulating the contextual assumptions that he has accessed in arriving at it. For example, the Type A interpretations of Soto's use of adios appear to be based on a relatively similar set of contextual assumptions. The writer of (8) rationalizes his interpretation of adios as 'a pretty acceptable response' by pointing to the immediate co-text of Soto's use of adios. The set of contextual assumptions that he appears to draw on relate to the precise manner in which the judge's dismissal of Soto was carried out, i.e., 'his [the judge's] cutesy “bye-bye”'. Similarly, the co-text appears to provide the most relevant contextual assumptions for (9), where Soto's use of adios is presented as a response to the 'childish' manner in which the judge 
has dismissed Soto. In each of these interpretations, the explicit meaning of Soto's utterance is 'good-bye' but when this input is synthesized with the contextual assumption that the judge is speaking to Soto in an informal and playful way, both draw the contextual implication that Soto's use of adios is intended to convey an acknowledgement of the familiarity implied by the judge's utterance by echoing that familiarity.

Type B interpretations tend to ignore the immediate co-text when processing Soto's use of adios. These interpretations (which I previously argued present Soto as indexing an oppositional stance because she does not show sufficient respect to the institutional setting) draw on contextual assumptions that relate to the courtroom setting, including the relative ranking of Soto and the judge, rather than on the linguistic co-text. The writer of (10A), for example, contrasts expectations about the "correct and ethical form of behavior in the courtroom" with Soto's actual behaviour: "giggling and smiling as if her being in there is a joke" implying that someone in Soto's position should conform to institutional expectations. The interpretation of Soto's intended meaning as up yours and other interpretations that see Soto's use of adios as intentionally offensive appear to derive from the pragmatic inference that adios is explicitly saying 'good-bye in a language other than the language of the court' and when this is synthesized with the contextual assumptions relating to the expectation that (a) the institutional setting, and the judge, should be respected and (b) respect is shown by using appropriate language, the contextual implication derived from Soto's use of adios (i.e., what Soto appears to mean by her use of that word) is something along the lines of "I do not respect the institution of the law".

Type $\mathrm{C}$ interpretations also draw on some of the contextual assumptions relating to the physical setting, but the primary set of contextual assumptions relate to the typical behaviour of girls. The writer of (12) for example draws the contextual implication that Soto is mocking the judge through her use of adios. The contextual assumptions that are articulated in justifying this interpretation include the assumption that some girls "think acting cute will get them out of trouble just because they're girls". The writer of (13) articulates a similar set of assumptions: "She thinks because she's a girl, she can get away with everything." There were a number of such interpretations in the data, where Soto is seen to have deserved the punishment meted out by the judge because she is attempting to exploit a particular type of privilege that accrues from being young and female:

(15) I think she's played her little manipulative cutesy game her whole life to get everything she wants (including Rick Ross's jewelry apparently) that she flipped out when it didn't work on a guy. 
These interpretations present Soto's use of adios as explicitly saying 'goodbye in a girlish way' and when this is synthesized with contextual assumptions such as 'girls get away with things by acting in a girlish way', Soto's use of adios is seen to be intending to convey a meaning along the lines of 'you can't punish me because I'm just a girl'. This specific set of interpretations also tends to express some pleasure in the judge's subsequent actions, since Soto's behaviour is seen as a failed attempt to manipulate him.

The analysis in this section has shown two things: firstly, that the different interpretations identified as a result of applying the first research question are informed by different contextual assumptions; and secondly, that context, in the specific sense it is used in relevance theory, does not precede an utterance but is constructed in the process of interpreting an utterance. For example, all the hearers of this YouTube clip had access to the knowledge that the setting of Soto's use of adios is a court of law; they all had access to the knowledge that in a court of law a judge is ranked higher than a defendant; they all had access to the knowledge that respect is realized through specific linguistic choices; they all had access to the knowledge that Soto is a girl and they all had access to the knowledge that the judge said bye-bye to Soto in a way that is not usual in a court of law. However, different elements of these, and of the many other assumptions that were potentially accessible to the hearers, were selected as relevant contexts in processing Soto's utterance. And the analysis has shown that depending on which contextual assumptions were accessed, different interpretations of her utterance were generated.

\section{Conclusion}

The theory of indexicality, as it has been developed in the past decade or so, is interested in accounting for patterned forms of indexing, and for this reason it has been of particular interest to sociolinguists (see Eckert 2012 for an extended treatment of this). However, the issues relating to indexicality I have raised in this paper are not self-evidently related to broad patterns of use. Adios will not, on the basis of Soto's individual use, have become a semiotic resource for indexing an oppositional stance. And it will not, on the basis of Soto's use, acquire the conventional meaning of up yours. The analysis above addresses the interpretations as nonce interpretations: it is designed to chart the way in which this specific use of adios has generated different meanings for different hearers. However, there are broader patterns to be found in the discourses or ideologies that inform these interpretations, so the interpretations are not just specific to an individual hearer. 
For example, the Type $\mathrm{C}$ interpretations are clearly informed by a discourse of femininity in which girls are constructed as vulnerable because of their gender and their youth. Soto's behaviour is perceived as manipulative because it exploits this construction of femininity. The Type $\mathrm{C}$ interpretations articulate a strong resentment towards the privilege that girls are seen to have and the unfair advantage that they are seen to be able to extract by exploiting their perceived vulnerability. Many comments also present Soto's manipulativeness as exploiting her sexual attractiveness, suggesting other discourses of gender are also playing a part in these interpretations. The Type B interpretations appear to be informed by a discourse in which a culture's institutions are perceived to be crucial to the perpetuation of that culture. Institutions, and individuals such as judges who have roles in those institutions, therefore must be protected if the culture is to be upheld. Within this discourse, by not conforming to the behaviour expected in a court of law, Soto's behaviour is seen as a threat to those institutions and the culture itself. Finally, many of the Type A interpretations appear to be informed by a discourse that has less respect for the status quo. Within this discourse the judge and the court are representative of a power hierarchy whose legitimacy and workings are open to question. The judge in such interpretations is presented as failing to take responsibility for his own behaviour.

My aim in this paper has been to show what an approach to (im)politeness evaluations that is informed by relevance theory and indexicality theory can bring to light about the exchange between the judge and Soto that would not be evident to most viewers of this clip and which also would not come to light in quite the same way through the application of other (im)politeness approaches to the courtroom data. The relevance theoretical approach I applied in Section 4 has brought into view (a) a range of different contextual assumptions that hearers of the exchange accessed in the process of interpreting the speakers' meanings, and (b) how differences in the attributed context led to different interpretations of the speakers' meanings. The indexical approach I applied in Section 3 complements these findings by showing that the different interpretations arise from differences in the typical situational dimensions that hearers associate with the linguistic resources adios and bye-bye. I have also demonstrated that indexicality theory can show how utterance interpretations relate to cultural knowledge, including assumptions about the discursive constructions of gender and institutions. 


\section{References}

Agha, Asif. 2003. The Social Life of Cultural Value. Language \& Communication 23. 231-273. Blakemore, Diane. 2011. Relevance theory. In Peter Grundy \& Dawn Archer (eds.). The Pragmatics Reader, 115-128. London: Routledge.

Blommaert, Jan. 2007. Sociolinguistics and discourse analysis: orders of indexicality and polycentricity. Journal of multicultural discourses 2. 115-130.

Brown, Penelope \& Stephen Levinson. 1987. Politeness: Some universals in language usage. Cambridge: Cambridge University Press.

Buchotlz, Mary. 2009. From Stance to Style: Gender, Interaction, and Indexicality in Mexican Immigrant Youth Slang. In Alexandra Jaffe (ed.). Stance: Sociolinguistic Perspectives, 146-170. New York: Oxford University Press.

Christie, Christine. 2007. Relevance theory and politeness. Journal of Politeness Research 3. 269-294.

Christie, Christine. 2013. The relevance of taboo language: An analysis of the indexical values of swearwords. Journal of Pragmatics 58. 152-169.

Christie, Christine. 2014. A Multimodal Analysis of the Metonymic Indexing of Power Relations in Novel and Film. In Christine Christie \& Arianna Maiorani. (eds.). Multimodal Epistemologies, 111-130. London: Routledge.

Christie, Christine. 2015. Epilogue. Politeness research: Sociolinguistics as applied pragmatics. Journal of Politeness Research 11. 355-364.

Culpeper, Jonathan. 2011. Impoliteness: Using Language to Cause Offence. Cambridge: Cambridge University Press.

Eckert, Penelope. 2008. Variation and the indexical field. Journal of Sociolinguistics 12. 453-476.

Eckert, Penelope. 2012. Three waves of variation study: the emergency of meaning in the study of sociolinguistic variation. Annual Review of Anthropology 41. 87-100

Moore, Emma \& Robert Podesva. 2009. Style, indexicality and the social meaning of tag questions. Language in Society. 38. 447-485.

Ochs, Elinor. 1996. Linguistic Resources for Socializing Humanity. In John Gumperz \& Stephen Levinson (eds.). Rethinking linguistic relativity, 407-438. Cambridge: Cambridge University Press.

Pizziconi, Barbara \& Christine Christie. 2017. Indexicality and Impoliteness. In Jonathan Culpeper, Michael Haugh \& Dániel Z Kádár (eds.). The Palgrave Handbook of Linguistic Politeness, 143-170. London: Palgrave.

Silverstein Michael. 2003. Indexical order and the dialectics of sociolinguistic life. Language and Communication 23. 193-229.

Silverstein, Michael. 2010. "Direct" and "indirect" communicative acts in semiotic perspective. Journal of Pragmatics 42. 337-353.

Sperber, Dan \& Deirdre Wilson. 1995. Relevance: Communication and cognition. Oxford: Blackwell.

Sperber, Dan, Francesca Cara \& Vittorio Girotto. 1995. Relevance theory explains the selection task. Cognition 57. 31-95.

Wilson, Deirdre. 2011. Parallels and differences in the treatment of metaphor in relevance theory and cognitive linguistics. Intercultural Pragmatics 8. 177-196.

Wilson, Deirdre \& Dan Sperber. 2012. Meaning and Relevance. Cambridge: Cambridge University Press. 


\section{Bionote}

\section{Christine Christie}

Christine Christie is a Senior Lecture in the School of Arts, English and Drama, Loughborough University. Her research interests and publications fall within these three fields of scholarship: language and gender, pragmatics and linguistic politeness. 